\title{
GRASSROOTS MATERNAL CHILD HEALTH LEADERSHIP CURRICULUM
}

\section{LINDSEY SKINNER, DEBORAH STIFFLER, NANCY SWIGONSKI, KARA CASAVAN, ASHLEY IRBY,} LARONA DIXON, AND JACK TURMAN JR.

\section{ABSTRACT}

In the United States, Indiana ranks $43^{\text {rd }}$ for its infant mortality rate. Twenty-nine of the 988 Indiana ZIP codes account for $27 \%$ of infant deaths. There is a need to train and mentor community members in these high risk ZIP codes to lead local maternal and child health (MCH) efforts that address the priorities of community members related to poor birth outcomes. A comprehensive grassroots MCH leadership curriculum is needed for this training process. We developed a curriculum designed to train community members in Indiana's high-risk ZIP codes to be grassroots maternal child health leaders (GMCHL). A team of public health faculty, clinicians, social service practitioners and community leaders developed the initial curriculum. Community feedback sessions that included grassroots community members, local clinicians and social service providers and non-profit leaders were conducted to get feedback on curriculum content. This feedback was incorporated to create the resulting grassroots $\mathrm{MCH}$ leadership training program. This curriculum provides a framework that can be used and adjusted to meet the needs of diverse communities across our nation to train residents to emerge as local $\mathrm{MCH}$ leaders that advocate for healthy pregnancies for all.
Keywords: social determinants of health, infant mortality, community development, policy advocacy, women's empowerment

\section{INTRODUCTION}

The measurement of infant mortality (IM) (death before an infant's first birthday) is used throughout the world as a key indicator of a nation's health and well-being (CDC, 2018). Among the United States, Indiana ranks $43^{\text {rd }}$ for its infant mortality rate (CDC, 2018). Twenty-nine of the 988 Indiana ZIP codes account for over one quarter (27\%) of infant deaths (Indiana State Department of Health [ISDH], 2017). Current approaches to address this problem include home visiting services, healthcare policy changes, increasing awareness among healthcare providers and interventions targeting individual health behaviors. Community-based grassroots efforts to raise the awareness and action of citizenry to address this vital public health problem and advocate with a community-centered voice is lacking. We are addressing this need by developing a curriculum, grounded in the Social Ecological Model (SEM) of Health Promotion (Bronfenbrenner, 1994), to train grassroots maternal and child health leaders (GMCHL) to lead community-based efforts to reduce infant mortality. 
Addressing societal factors by equipping GMCHL to be health and social change agents is crucial to creating and sustaining a culture that promotes neighborhood health. Previous studies demonstrate that fostering community leaders for community-based health promotion efforts resulted in program sustainability, incorporation of health promotion elements into non-health sector community institutions and mediated the creation of multisector teams in the community to address health problems (Goodman \& Steckler, 1987/88; Orlandi, 1986; Shediac-Rizkallah \& Bone, 1998. Our approach builds on the previous work of others by incorporating the lifecourse theory (Lu \& Halfton, 2003), a place- and community-based approach (Gabbe et al., 2017; Pies, Barr, Strouse, \& Kotelchuck,, 2016) and bringing the community in as its own specific discipline (Reynolds et al., 2015; Smith, Tiwari, \& Lommerse, 2014). This manuscript presents the process of developing and testing this curriculum for training GMCHL. A detailed $\mathrm{MCH}$ leadership training curriculum for grassroots community leaders is missing from the literature. The curriculum we developed can be applied to community development activities in a diverse range of neighborhoods that are struggling with persistent adverse birth outcomes.

\section{MATERIALS AND METHODS}

\section{Curriculum Overview}

Our curriculum is grounded in transformative andragogy (Knowles, 1973), which is one of the foundations of modern adult learning theory (Merriam, 2001). Transformative andragogy proposes that adults learn differently than children based on four assumptions: changes in self-concept; the role of experience; readiness to learn; and orientation to learning. We incorporated the distinguishing characteristics of adult learning (Goad, 1982; Hanson, 1981) into each module. As the curriculum builds through each module, it promotes a learning process where each participant is actively involved and responsible for his/her learning. Time and activities are given during each session for the GMCHL to reflect on their previous experiences and relate to what they are learning. The curriculum uses images and quotes to evoke emotional responses from the GMCHL and data to appeal to their intellectual learning. The goal is to combine the knowledge and expertise of the facilitator with that of the GMCHL, thus creating new knowledge for optimal community development work (Smith, Tiwari \& Lommerse, 2014). Learning objectives were created using Bloom, Engelhart, Furst, Hill, and Krathwohl (1956) taxonomy. Learning objectives were designed to correlate with the MCH Leadership Competencies developed by the MCH Leadership Training Conference (2009).

Every attempt is made to present the information at a level that is easily understandable as $14.7 \%$ of adults lack basic literacy skills and $13.6 \%$ lack below basic literacy skills (National Center for Education Statistics, 2003). For GMCHL to be empowered as agents of change to improve $\mathrm{MCH}$ health outcomes, they need to be equipped with terminologies used at the public health, medical, and policy making levels. To this end, we define and use terminology that is used in the aforementioned sectors. As words or terms are identified that are unknown or confusing during the curriculum, we 
create a vocabulary list for the GMCHL and work with them during mentoring sessions on the correct use of these terms. In addition, we will ask the GMCHL to provide lists of terms/phrases that are used to describe $\mathrm{MCH}$ conditions experienced in their community. Together we will develop health communication strategies to optimize the dissemination of $\mathrm{MCH}$ information in the community.

The original draft of the curriculum was developed by a team consisting of: public health faculty, practicing nurses, physicians, social service providers, government public health workers, and local $\mathrm{MCH}$ non-profit leaders. The curriculum is divided into four sequential modules. All training and mentoring occurs in community sites that are easily accessible for participants. The knowledge content of the curriculum is centered around the following themes: leadership development and community health promotion, understanding adverse birth outcomes, health equity, and community and policy development. The initial training focused on these themes lasts four months. The curriculum allows for flexibility in scheduling and the GMCHL determine how and when they complete the sessions. During the initial four months, the GMCHL will also be trained in the following skills to help them build their leadership capacity.

Photovoice. The Photovoice method is a CBPR method used for the development and implementation of community health assessments and program planning. Photovoice was successfully used to educate community leaders and policy makers about $\mathrm{MCH}$ issues in their neighborhoods (Wang \& Burris, 1997).
Each GMCHL will be trained in the Photovoice method and provided a digital camera to document strengths and concerns of their community. Trained program staff will facilitate discussion of the photos utilizing the following questions: what do you see here, what is happening here, how does this relate to your life and the lives in the neighborhood, why does this situation, concern, or strength exist, and what can we do about this?

Storytelling. GMCHL will complete multiple storytelling workshops led by collaborators from the Department of Anthropology. This process helps the GMCHL develop skills in telling their personal story and the story of their neighborhood. The training sessions will cover the fundamentals of good stories, interview tips, writing exercises, and an opportunity for the GMCHL to draft their own story.

Policy Advocacy. Our partner, the Indiana Institute for Working Families provided curriculum to teach the GMCHL skills in policy development and advocacy. Following training, they will help GMCHL form partnerships with their local representatives to begin policy advocacy for $\mathrm{MCH}$ promotion.

EvaluLead. The EvaluLead model will be used to guide and evaluate community priorities. This evaluation tool was developed by a partnership of the Public Health Institute, the W.K. Kellogg Foundation and the US Agency for International Development (Grove et al., 2005). The tool utilizes an open-systems approach for guiding and evaluating community leadership development based on values, norms and performance factors, and results in leadership goals at community, organizational and individual levels. 
The goal is that after the four months, the GMCHL will have the foundation to begin their work while being continuously mentored.

\section{Soliciting Curriculum Feedback}

To ensure that our curriculum is comprehensive, we solicited input from 26 community members that represent a wide range of age, race/ethnicity, work expertise (grassroots citizens passionate about $\mathrm{MCH}$, local health and social service providers, local government public health workers, non-profit leaders) and cultural backgrounds. In these sessions, we presented a summary of our initiative, themes from the four curricular modules, and key objectives and highlights from each module. A questionnaire was used for evaluation that included the following: name three things you learned from the information presented, what should we do better with this curriculum, how can grassroots leadership development impact the health of your neighborhood, what part of the curriculum did you find to be the most helpful, what part of the curriculum did you find to be the least helpful, how did the information presented change you, and has the information presented changed how you view the relationship between the characteristics of your community and the health of women, children, and families living in your community? Following the discussion of the questionnaire, an open discussion was held to solicit feedback driven by the participants. In addition to these community sessions, we received extensive feedback on the entire curriculum from: a child psychiatrist with a specialization in maternal and infant attachment, the lead case manager of Healthy
Start for Marion County, and staff from the Indiana Institute for Working Families, the Urban League of Indianapolis and the Indiana Rural Health Association. A thematic analysis (Braun \& Clark, 2006) was performed to synthesize the feedback from all of the community members. Changes were integrated into the curriculum.

\section{RESULTS}

Our results are organized by the four curricular modules, inclusive of feedback regarding each module, a detailed presentation of the learning objectives, correlation to $\mathrm{MCH}$ competencies (MCH Leadership Competencies Workgroup, 2009), knowledge and skill building activities and associated learning activities for each curriculum session.

\section{Module 1: Leadership in a Maternal Child Health}

\section{Context}

Many reviewers expressed the importance of recruiting community members to be the main facilitators of building the capacity of the neighborhood to support healthy birth outcomes. Other feedback included the need to conduct a strengths asset analysis of GMCHL to help them understand their personal strengths from which to build their leadership. The overwhelming majority of reviewers expressed the great need for this $\mathrm{MCH}$ training approach that emphasizes skill building and action to complement the current work in Indiana. Using this feedback and the work of our team resulted in the curriculum details of module 1 (Table 1 ).

\section{Module 2: Adverse Birth Outcomes}


Most reviewers expressed their great surprise at the persistent IM problem in communities across Indiana, especially those reviewers who resided or worked in several of the high-risk ZIP codes. In module two, the context of pregnancy is introduced to describe how the health of a woman before she becomes pregnant can determine how healthy her pregnancy will be. Some reviewers expressed the need to include information on interconception, family planning, depression [specifically the differences between depression, postpartum depression, and baby blues] and domestic violence. Other reviewers discussed the importance of teaching the GMCHL health communication strategies to disseminate the information they will learn to members of the community. Some reviewers expressed concern that the GMCHL would lack the ability to understand statistics such as IM, preterm birth, and low-birth-rate calculations. Using this feedback and the work of our team resulted in the curriculum details of module 2 (Table 2).

\section{Module 3: Equity for All Babies}

Feedback for module three included the significance of sharing data on birth disparities and inequities in communities, defining disparity, equality, and equity, and sharing disparities in birth outcomes for people in Indiana based on race and geographic location. Two curriculum reviewers did not agree with sharing a table that showed similarities in birth outcomes in three high-risk Indiana ZIP codes with Iraq, Syria, and Libya as they were concerned the data were not accurate since it came from other countries. The same reviewers also did not agree with sharing statistics that showed African-American infants are two to three times more likely to die than their white peers. Their concern was that this did not properly highlight the work being done currently to reduce this disparity. However, the majority of reviewers discussed how important it is to share data with the GMCHL regarding all forms of birth disparities. The majority of reviewers also found it to be powerful to show that some of the high-risk ZIP codes in Indiana have similar or worse IM compared to our war-torn or politically unstable countries. Reviewers found it very helpful to discuss the impact of chronic stress on biological systems associated with pregnancy. They believed that this would be very helpful in validating the beliefs about stress observed throughout local communities. Using this feedback and the work of our team resulted in the curriculum details of module 3 (Table 3 ).

\section{Module 4: Power of Community Engagement}

The multi-sector reviewers found the use of storytelling and Photovoice to be powerful tools to capture the voice and story of the community. There was great consensus that the community realities surrounding IM are not prioritized in our state and that there is a paucity of community action approaches to complement health care approaches. Feedback was given concerning the type of questions the GMCHL would answer during Photovoice, the amount of time they would have to take the photos, and the Photovoice training process. During this session the GMCHL also get introduced to using the EvaluLead tool to make their community leadership plan. Using this feedback and the work of our team resulted in the curriculum details of module 4 (Table 4 ). 


\section{DISCUSSION}

While developing this curriculum we received a wide range of feedback to ensure the curricular content is inclusive of all necessary topics. It was evident in receiving feedback from our multi-sector partners, that developing $\mathrm{MCH}$ community leaders is needed to build the capacity of the community to support positive $\mathrm{MCH}$ outcomes. It was widely acknowledged that building their skills (i.e. Photovoice, storytelling, policy development, EvaluLead) will equip them from just having knowledge to being able to act on the knowledge. Likewise, it was pointed out that GMCHL would foster new knowledge of healthcare providers and policy makers, thus helping them better perform their duties. It was widely acknowledged that community members are not usually incorporated into decision making discussions that impact $\mathrm{MCH}$ practices and policies for their community. Leaders who are from and/or based in their community better understand the challenges and strengths of their community. This allows for a better community needs assessment, priority setting, and identification of necessary solutions that ultimately leads to community development that better supports community members and their birth outcomes (Harper-Hannigan et al., 2017). One challenge we faced in developing this curriculum and its review process was accessing grassroots community members who could help in its development and review process. We often were presented with community organization leaders to provide feedback, but not grassroots community members who have direct or indirect experience with adverse birth outcomes. To overcome this, we worked in partnership with the Indianapolis Urban League to connect with community members who are participating in some of their programs. Our Urban League partner greatly supported this effort. She emphasized the lack of knowledge among citizens regarding infant mortality and the persistent disparities associated with this problem. She and the individuals she connected us with were vital in providing feedback regarding the use of data in the curriculum and the need for community leaders training.

The main objective of the training curriculum is to provide GMCHL with the foundation necessary to begin their community efforts. These GMCHL will represent community as an equally important discipline in Indiana IM reduction strategies (Smith et al., 2014), filling the gap of grassroots community participation in decision making that influences local MCH outcomes. Our leadership development model is linked to the Smith, Tiwari \& Lommerse (2014) community development framework, which posits that decision-making, empowerment, and participation are all necessary and continuous processes for community development and that “...community-based capacity building is both a prerequisite and an outcome of community development.” Through this framework, the social capital of the GMCHL will be further developed, thereby increasing their civic engagement, trust and reciprocity of fundamental information exchange between community members (Bourdieu, 1986). Building community capacity in neighborhoods at risk for poor outcomes will result in an improvement to community members' abilities to cope with adversity and limitations, foster a sense of place (McMurray \& Clendon, 2011) and help lead the 
physical, social, economic or environmental transformation (Smith et al., 2014) of their neighborhood to support improved birth outcomes.

It is widely recognized that access to data and its collective analysis by community members, researchers and clinicians is vital to the success of a community-based effort at improving health or social outcomes (Israel, Shulz, Parker, \& Becker, 1998). Often community members do not have access to data that pertain to their communities, thus further isolating them from making informed decisions about their community needs. Throughout feedback sessions we learned that community members as well as health and social service professionals were not aware of the IM issues facing Indiana communities. Our training program will provide GMCHL with data that promote their basic understanding of Indiana's adverse birth outcomes, their risk factors, and birth disparities impacting U.S., Indiana and local communities. With this foundational understanding, GMCHL will emerge as community experts who are skilled participants and decision makers in multi-sectorial MCH discussions.

Clinical interventions alone cannot reduce infant mortality because birth outcomes, like overall health, are the product of one's environment, opportunities and experiences (Collins, Wambach, David, \& Rankin, 2009). Building a community's health promotion capacity is essential to any coordinated effort aimed at improving and sustaining health outcomes (LaBonte, Woodard, Chad, \& Laverack, 2002). As evidenced by the gap in the literature, and feedback received from a wide array of individuals passionate about improving birth outcomes across Indiana, our priority to develop and mentor ZIP-code based GMCHL is not only unique but needed. We implemented a process to develop a curriculum that is adaptable to any community and addresses the many factors needed to be a successful GMCHL. As we begin to implement this by training community members, we will continuously seek their feedback on curriculum content and delivery to make sure we are optimizing their learning experience and future participant's learning experiences.

\section{ACKNOWLEDGMENTS}

We thank our partners: the Harrison Center, Indiana Institute of Working Families, Indiana State Department of Health, Indianapolis Urban League, Marion County Public Health Department, Riley Children's Foundation, Indiana Rural Health Association and everyone who took the time to review the curriculum and provide feedback.

DECLARATION OF INTEREST STATEMENT

The authors do not have any conflicts of interest. 


\section{Table 1:}

Module 1 Components

\begin{tabular}{|c|c|}
\hline $\begin{array}{l}\text { Learning Objectives: where applicable can accommodate MCH } \\
\text { Learning Competencies (2009) }\end{array}$ & Knowledge (k), Skills (s), and Activity (a) components \\
\hline $\begin{array}{l}\text { 1. Describe the role that community leaders play in maternal and child } \\
\text { health development. }\end{array}$ & Individuals must be considered within their social environment (k). \\
\hline $\begin{array}{l}\text { 2. Define community capacity building and the importance in improving } \\
\text { local maternal and child health issues. }\end{array}$ & $\begin{array}{l}\text { Characteristics of community-based health promotion programs }(\mathrm{k}) \text {. } \\
\text { Importance of community leaders }(\mathrm{k}) \text {. } \\
\text { Need healthy neighborhoods for healthy pregnancies, infants, and families } \\
(\mathrm{k})\end{array}$ \\
\hline $\begin{array}{l}\text { 3. Define leadership development in the context of community capacity } \\
\text { building ( } \mathrm{MCH} \text { competency } 2 \text { ). }\end{array}$ & $\begin{array}{l}\text { Define leadership (k). } \\
\text { Command and Control, Servant, and Transformational leadership styles } \\
\text { (k). }\end{array}$ \\
\hline $\begin{array}{l}\text { 4. Demonstrate ability to identify personal leadership skills (MCH } \\
\text { competency 2). }\end{array}$ & $\begin{array}{l}\text { Self-reflection's importance in leadership (k). } \\
\text { Recognize inherent leadership qualities as well as those that need to be } \\
\text { cultivated (s). } \\
\text { Leadership style activity (a). }\end{array}$ \\
\hline $\begin{array}{l}\text { 5. Complete and analyze a personal strengths inventory to gain insight } \\
\text { into innate personal leadership qualities (MCH competency 2). }\end{array}$ & $\begin{array}{l}\text { Formulate self-reflection leadership skills (s). } \\
\text { Strengths inventory of leadership skills (a). }\end{array}$ \\
\hline $\begin{array}{l}\text { 6. Recognize optimal health promotion programming requires action at } \\
\text { the individual, interpersonal, organizational, community, and public } \\
\text { policy levels. }\end{array}$ & $\begin{array}{l}\text { Neighborhood is the agent for change (k). } \\
\text { SEM of Health Promotion (Bronfenbrenner, 1994) (k). }\end{array}$ \\
\hline 7. Differentiate policy issues for women at various points in the lifespan. & $\begin{array}{l}\text { Women's health across the lifespan (k). } \\
\text { Policy concerns during child, teen, adult, and older adult years (k) }\end{array}$ \\
\hline $\begin{array}{l}\text { 8. Provide examples of the relationship between healthy communities and } \\
\text { healthy pregnancies. }\end{array}$ & $\begin{array}{l}\text { GMCHL provide examples from personal experience or learning that } \\
\text { demonstrate the connection between healthy neighborhoods and } \\
\text { pregnancies (a). }\end{array}$ \\
\hline $\begin{array}{l}\text { 9. Discuss intergenerational differences in life experiences and how this } \\
\text { can shape different perspectives and conversations with community } \\
\text { members. }\end{array}$ & $\begin{array}{l}\text { Traditionalist, Baby Boomer, Generation Xer, and Millennial generations } \\
(\mathrm{k}) \text {. } \\
\text { Highlight historical events that happened during different generations (k). } \\
\text { Introduce common values held by each generation (k). } \\
\text { Introduce the idea that our life experiences shape who we are, how we } \\
\text { view the world, and communicate (k). }\end{array}$ \\
\hline
\end{tabular}




\section{Table 2:}

\section{Module 2 Components}

\begin{tabular}{|c|c|}
\hline $\begin{array}{l}\text { Learning Objectives: where applicable can accommodate MCH } \\
\text { Learning Competencies (2009) }\end{array}$ & Knowledge (k), Skills (s), and Activity (a) components \\
\hline $\begin{array}{l}\text { 1. Define infant mortality, preterm birth and low birth weight (MCH } \\
\text { competency 4). }\end{array}$ & $\begin{array}{l}\text { Learn current CDC definitions of IM, preterm birth, and low-birth-weight } \\
(\mathrm{k}) \text {. }\end{array}$ \\
\hline 2. Discuss risk factors for adverse birth outcomes. & $\begin{array}{l}\text { Premature rupture of membranes, intrauterine infections, genetic } \\
\text { abnormalities, multiple pregnancies/fertility treatments, birth spacing, } \\
\text { maternal age, history of preterm birth, chronic stress, drugs of abuse, and } \\
\text { domestic violence (k). }\end{array}$ \\
\hline $\begin{array}{l}\text { 3. Compare/contrast the context of pregnancy for women in the USA and } \\
\text { Indiana. }\end{array}$ & $\begin{array}{l}\text { Learn current March of Dimes and NIMH data given on national and IN } \\
\text { rates of obesity, depression, late or no prenatal care, smoking and binge } \\
\text { alcohol use for women ages } 18-44 .(\mathrm{k}) \text {. } \\
\text { Discuss similarities/differences in data (a). }\end{array}$ \\
\hline 4. Differentiate depression, postpartum depression and baby blues. & $\begin{array}{l}\text { Learn current NIMH and CDC definitions of depression, postpartum } \\
\text { depression and baby blues (k). } \\
\text { Discuss similarities/differences (a). }\end{array}$ \\
\hline 5. State what to do if someone is severely depressed or suicidal. & $\begin{array}{l}\text { Share National Suicide Prevention Lifeline and treatment options (k). } \\
\text { Discuss what to do in crisis (a). }\end{array}$ \\
\hline $\begin{array}{l}\text { 6. Describe difficulties preterm infants can have later in life if they survive } \\
\text { infancy. }\end{array}$ & $\begin{array}{l}\text { Cerebral palsy, blindness, hearing loss, and learning, breathing, or feeding } \\
\text { problems }(\mathrm{k}) \text {. } \\
\text { Differences in infant brain at } 31 \text { and } 40 \text { weeks }(\mathrm{k}) \text {. }\end{array}$ \\
\hline $\begin{array}{l}\text { 7. Explain the importance of maternal-infant attachment and why } \\
\text { communities should support this bond. }\end{array}$ & $\begin{array}{l}\text { Foundational for physical, cognitive, and emotional development and } \\
\text { provides benefits for mothers, infants, children, families, and communities } \\
\text { (k). } \\
\text { Poor attachment can cause behavioral disturbances, poor peer } \\
\text { relationship, feeding difficulties, and emotional regulation problems }(\mathrm{k}) \text {. } \\
\text { Communities must support healthy maternal-infant attachment }(\mathrm{k}) \text {. }\end{array}$ \\
\hline 8. Contrast unsafe infant sleeping with safe infant sleeping. & $\begin{array}{l}\text { 1/16 infant deaths in Indiana are due to unsafe infant sleeping that are } \\
100 \% \text { preventable (SUIDs not SIDS) (k). } \\
\text { AAP's (2016) ABCDE's of safe sleep (k). } \\
\text { Discuss safe and unsafe infant sleep images (a). }\end{array}$ \\
\hline 9. Identify infant sleeping myths. & $\begin{array}{l}\text { Four myths: they will choke lying on their back, they will catch a chill, I } \\
\text { bond best sleeping with my baby, and it looks like a prison (k)). } \\
\text { Discuss other myths they have heard and how they might refute them (a). }\end{array}$ \\
\hline $\begin{array}{l}\text { 10. Distinguish differences in how infant mortality, preterm birth, and } \\
\text { low-birth weight rates are calculated. }\end{array}$ & $\begin{array}{l}\text { Teach current CDC calculations of IM, preterm birth, low-birth-weight } \\
\text { (k). }\end{array}$ \\
\hline $\begin{array}{l}\text { 11. Compare/Contrast differences in infant mortality, preterm birth, and } \\
\text { low-birth weight rates at the national, state, county, and local levels. }\end{array}$ & $\begin{array}{l}\text { Learn current March of Dimes infant mortality, preterm birth, and low- } \\
\text { birth-weight data for U.S., Indiana, the county of the GMCHL and the ZIP } \\
\text { code of the GMCHL }(\mathrm{k}) \text {. }\end{array}$ \\
\hline 12. Identify Indiana priorities for reducing infant mortality. & Unsafe infant sleeping and premature birth $(\mathrm{k})$. \\
\hline 13. Identify Indiana priorities in accessing services. & $\begin{array}{l}\text { Prenatal care, WIC, mental health care, transportation, physical activity, } \\
\text { and smoking reduction }(\mathrm{k}) \text {. } \\
\text { Discuss where people in their community go for these services (a). }\end{array}$ \\
\hline $\begin{array}{l}\text { 14. Rehearse a sample presentation wherein you have to teach the local } \\
\text { community members about infant mortality, preterm birth, low birth } \\
\text { weight, and their associated causes and consequences. (MCH competency } \\
\text { 4). }\end{array}$ & $\begin{array}{l}\text { Principles of health communication (k). } \\
\text { Develop skills in presenting data and information to lay audiences (s). } \\
\text { Develop skills in public speaking (s). } \\
\text { Present to the facilitator and other GMCHL (a). }\end{array}$ \\
\hline
\end{tabular}




\section{Table 3:}

\section{Module 3 Components}

\begin{tabular}{|c|c|}
\hline $\begin{array}{l}\text { Learning Objectives: where applicable can accommodate MCH } \\
\text { Learning Competencies (2009) }\end{array}$ & Knowledge (k), Skills (s), and Activity (a) components \\
\hline $\begin{array}{l}\text { 1. Discuss the range of disparities in health outcomes and discuss how } \\
\text { health equity is applied to address this. (MCH competency 2). }\end{array}$ & Use Whitehead (1991) definition of disparity, equality, and equity (k). \\
\hline 2. Contrast race and ethnicity. & $\begin{array}{l}\text { Learn definitions of race and ethnicity (k). } \\
\text { Discuss their thoughts on race and/or ethnicity (a). }\end{array}$ \\
\hline $\begin{array}{l}\text { 3. Differentiate birth outcomes in the USA, Indiana, and globally within } \\
\text { the context of disparities. }\end{array}$ & $\begin{array}{l}\text { Comparative analysis of birth outcomes across race/ethnicity, immigrants, } \\
\text { global community }(\mathrm{k}) \text {. }\end{array}$ \\
\hline 4. Discuss the different types of birth disparities in their community. & Highlight ZIP-code specific birth disparities for their community (k). \\
\hline 5. Contrast differences between acute and chronic stress. & $\begin{array}{l}\text { Compare/contrast acute, chronic, minor, and major types of stress (k). } \\
\text { Show the effects of chronic minor and major and acute major stress on the } \\
\text { body's hormonal, cardiovascular, and immunological systems (k). } \\
\text { Provide examples of chronic minor and major and acute major stress's } \\
\text { effect on pregnancy and birth outcomes (k). }\end{array}$ \\
\hline $\begin{array}{l}\text { 6. Complete a personal adverse childhood experiences (ACES) survey to } \\
\text { increase awareness of the range of life experiences that contribute to } \\
\text { chronic stress. }\end{array}$ & $\begin{array}{l}\text { Recognize how incidents that happen to us as children shape our lives } \\
\text { later on (k). } \\
\text { Continuation of the self-reflection process. Looking internally to see how } \\
\text { their experiences have shaped their lives (s). } \\
\text { ACES activity (a) }\end{array}$ \\
\hline $\begin{array}{l}\text { 7. Explain how chronic stress is related to birth disparities and differences } \\
\text { in maternal and child health outcomes for different communities and } \\
\text { groups of people. }\end{array}$ & $\begin{array}{l}\text { Discuss how chronic stress reduces an individual's ability to make healthy } \\
\text { choices especially regarding smoking, diet, exercise, alcohol, or illicit drug } \\
\text { use (k). } \\
\text { Changes in the neuroendocrine, vascular, and immune-inflammatory } \\
\text { pathways can impact a mother's pregnancy leading to adverse birth } \\
\text { outcomes (k). }\end{array}$ \\
\hline 8. State ways to reduce chronic stress. & $\begin{array}{l}\text { Identify stress reduction techniques (k). } \\
\text { Discuss advice they would give others to reduce stress (a). }\end{array}$ \\
\hline $\begin{array}{l}\text { 9. Develop a list of community resources that can be used to promote } \\
\text { equitable birth outcomes ( } \mathrm{MCH} \text { competency } 3 \text { ). }\end{array}$ & $\begin{array}{l}\text { Create a list of community resources and assets that can address barriers } \\
\text { to } \mathrm{MCH} \text { promotion (a). }\end{array}$ \\
\hline
\end{tabular}




\section{Table 4:}

\section{Module ${ }_{4}$ Components}

\begin{tabular}{|c|c|}
\hline $\begin{array}{l}\text { Learning Objectives: where applicable can accommodate MCH } \\
\text { Learning Competencies (2009) }\end{array}$ & Knowledge (k), Skills (s), and Activity (a) components \\
\hline $\begin{array}{l}\text { 1. Outline one's role as a grassroots maternal and child health leader to } \\
\text { build the capacity of their community to improve birth outcomes and } \\
\text { maternal and child health. }\end{array}$ & $\begin{array}{l}\text { Define aim as building community capacity to support healthy women, } \\
\text { infants, and families }(\mathrm{k}) \text {. } \\
\text { Community members must identify the problems, solutions, and action } \\
\text { plans }(\mathrm{k}) \text {. } \\
\text { This empowers the community and improves the individuals' health } \\
\text { status, behaviors, and coping }(\mathrm{k}) \text {. } \\
\text { Share community-based model (k). }\end{array}$ \\
\hline $\begin{array}{l}\text { 2. Apply knowledge of the social ecological model in suggesting ways to } \\
\text { improve maternal and child health in their community. }\end{array}$ & $\begin{array}{l}\text { Re-introduce SEM model (k). } \\
\text { Develop skills in identifying MCH in the different levels of the SEM (s). } \\
\text { Have GMCHL identify ways to improve MCH health in each level of the } \\
\text { SEM (a). }\end{array}$ \\
\hline 3. Develop appreciation of being a mindful leader. & Discuss importance of being mindful as a leader $(\mathrm{k})$ \\
\hline $\begin{array}{l}\text { 4. Practice mindfulness exercise and describe how to incorporate this into } \\
\text { daily activities. }\end{array}$ & $\begin{array}{l}\text { Mindfulness exercise (k). } \\
\text { Develop skills in being a mindful leader (s). } \\
\text { Mindfulness activity (a). }\end{array}$ \\
\hline $\begin{array}{l}\text { 5. Summarize importance of storytelling as it pertains to maternal and } \\
\text { child health. }\end{array}$ & $\begin{array}{l}\text { Storytelling can be used to make a point or convey a message and to } \\
\text { facilitate discussions }(\mathrm{k}) \text {. } \\
\text { Being a good leader means listening to others' stories }(\mathrm{k}) \text {. }\end{array}$ \\
\hline $\begin{array}{l}\text { 6. Develop, in an impromptu session, a personal story that highlights the } \\
\text { need for taking actions to improve birth outcomes (MCH competency 5). }\end{array}$ & $\begin{array}{l}\text { Developing storytelling skills (s). } \\
\text { Present a story (a). }\end{array}$ \\
\hline 7. Describe goals and basic practice of Photovoice. & Describe process of Photovoice $(\mathrm{k})$ \\
\hline $\begin{array}{l}\text { 8. Discuss the use of Photovoice to improve birth outcomes in your } \\
\text { community. }\end{array}$ & $\begin{array}{l}\text { Discuss } 4 \text { guiding questions of Photovoice: who makes up families in your } \\
\text { neighborhood, document "mom's story" with } 3 \text { pregnant women and } 3 \\
\text { mothers, what are sleeping environments of babies in your neighborhood, } \\
\text { and what is your role as a change agent in the community }(\mathrm{k}, \mathrm{a}) \text {. }\end{array}$ \\
\hline 9. Describe basic process of policy development (MCH competency 12). & $\begin{array}{l}\text { The following information is provided by Indiana Institute for Working } \\
\text { Families: The composition of the Indiana House of Representatives and } \\
\text { the Senate, registering to vote, identifying IN lawmakers, how a bill } \\
\text { becomes a law in Indiana, and how to approach their lawmaker }(\mathrm{k}, \mathrm{s}, \mathrm{a}) \text {. }\end{array}$ \\
\hline 10. Differentiate policy issues for women at various points in the lifespan. & $\begin{array}{l}\text { Childhood: preschool, brain development, immunizations, and family } \\
\text { support (k). } \\
\text { Teen years: prevention of STD's, pregnancy, and smoking, drugs of abuse, } \\
\text { and alcohol use (k). } \\
\text { Adulthood: interconception, preventative health services, child raising, } \\
\text { quality childcare, and parental support (k). } \\
\text { Old adulthood: raising grandchildren and managing chronic diseases (k). } \\
\text { Discuss different policy issues for women across the lifespan that are not } \\
\text { included (a). }\end{array}$ \\
\hline $\begin{array}{l}\text { 11. Identify a policy to improve women's health and a personal strat } \\
\text { advance this policy (MCH competency 12). }\end{array}$ & $\begin{array}{l}\text { Help them develop skills in making a policy action plan (s). } \\
\text { Identify a policy that they would like to advance to promote MCH (a). }\end{array}$ \\
\hline
\end{tabular}




\section{REFERENCES}

American Academy of Pediatrics [AAP]. (2016).

American Academy of Pediatrics Announces

New Safe Sleep Recommendations to Protect

Against SIDS, Sleep-Related Infant Deaths.

Retrieved from https://www.aap.org/en-

us/about-the-aap/aap-press-

room/pages/american-academy-of-pediatrics-

announces-new-safe-sleep-recommendations-

to-protect-against-sids.aspx

Bloom, B., Engelhart, M., Furst, E., Hill, W., \&

Krathwohl, D. (1956). Taxonomy of educational

objectives: The classification of educational

goals. Handbook I: Cognitive domain. New

York, NY: Association of College and

University Examiners.

Bourdieu, P. (1986). The Forms of Capital. In J.

Richardson (Ed.), Handbook of Theory and

Research for Sociology of Education, pp. 241-

258. Westport: Greenwood.

Braun, V. \& Clarke, V. (2006). Using thematic analysis in psychology. Qualitaitve Research in Psychology, 3(2), 77-101. Retrieved from https://search.proquest.com/docview/22313552 1? accountid $=7398$

Bronfenbrenner, U. (1994). Ecological models of human development. In International Encyclopedia of Education. (Vol. 3, 2nd ed., pp. 1643-1647). Oxford: Elsevier.

Collins, J., Wambach, J., David, R., \& Rankin, K. (2009). Women's lifelong exposure to neighborhood poverty and low birth weight: A population- based study. Maternal and Child Health

Journal, 13(3), 326-333. doi:10.1007/s10995-0o80354-0

Centers for Disease Control and Prevention [CDC]. (2018). Infant Mortality. Retrieved from https://www.cdc.gov/reproductivehealth/mate rnalinfanthealth/infantmortality.htm

Gabbe, P., Reno, R., Clutter, C., Schottke, T., Price, T., Calhoun, K., Lynch, C. (2017). Improving maternal and infant child health outcomes with community-based pregnancy support groups: Outcomes from Moms2B Ohio. Maternal Child Health Journal, 21, 1130-1138. doi: 10.1007/s10995-016-2211-X

Goodman, R. \& Steckler, A. (1987/88). The life and death of a health promotion program: an institutionalization case study. International Quarterly of Community Health Education, 8(1), 5-22. doi: 10.219o/ $\mathrm{E}_{5} \mathrm{H}_{5-3} \mathrm{NoA}-\mathrm{XN}_{9} \mathrm{~N}-$ FQ9X.

Goad, T. (1982). Delivering effective training. San Diego, CA: Pfeiffer \& Company.

Grove, J., Kibel, B., \& Haas, T. (2005). Evalulead: a guide for shaping and evaluating leadership development programs. Oakland, CA: The Public Health Institute. Hanh, T. (2007). The art of power. New York, NY: Harper Collins.

Hanson, P. (1981). Learning through groups: A trainer's basic guide. San Diego, CA: Feiffer \& Company. Harper-Hanigan, K., Ross, G., Sims, T., Trotter, K., \& Turman Jr., J. (2017). Women's perspectives of needs surrounding adverse birth outcomes: A 
qualitative assessment of the neighborhood impact of adverse birth outcomes. Maternal and Child Health Journal, 21,2219-2228. doi:10.1007/s10995-017-2343-7

Indiana State Department of Health [ISDH]. (2017). Retrieved from https://www.in.gov/isdh/ http://www.in.gov/isdh/27470.htm

Israel, B.A., Schulz, A.J., Parker, E.A., Becker, A.B. (1998). Review of community-based research: Assessing partnership approaches to improve public health. Annual Review of Public Health, 19:173-202.

Knowles, M. (1973). The Adult Learner: A Neglected Species. Houston, TX: Gulf Publishing Company.

LaBonte, R., Woodard, G., Chad, K., \& Laverack, G. (2002). Community capacity building: a parallel track for health promotion programs. Canadian Journal of Public Health, 93(3), 181182. Retrieved from https://www.ncbi.nlm.nih.gov/pubmed/120509 83

Lu, M., \& Halfton, N. (2003). Racial and Ethnic Disparities in Birth Outcomes: A Life-Course Perspective. Maternal and Child Health Journal, 7(1), 13-30. doi: 1092-7875/03/0300-0013/o

MCH Leadership Competencies Workgroup. (2009).

Maternal and Child Health Leadership

Competencies Version 3.o. Retrieved from

https://leadership.mchtraining.net/mchlc doc s/mch leadership comp 3-0.pdf
McMurray, A., \& Clendon, J. (2011). Community Health and Wellness: Primary Health Care in Practice. New York, Elsevier.

Merriam, S. (2001). Andragogy and Self-Directed Learning: Pillars of Adult Learning Theory. New Directions for Adult $\mathcal{E}$ continuing Education, 89(3), 3-11. Retrieved from http://web.a.ebscohost.com/ehost/pdfviewer/p dfviewer?vid=2\&sid=ezeed 2a2-7046-48d4a283-ab5bogfd7bae\%40sessionmgr40o6

National Center for Education Statistics. (2003). State $\mathcal{E}$ County Estimates of Low Literacy. Retrieved from

https://nces.ed.gov/naal/estimates/overview.as $\mathrm{px}$

Orlandi, M. (1986). Community-based Substance Abuse Prevention: A Multicultural Perspective. Journal of School Health, 56(9, 394-401. doi: 10.1111/j.1746-1561.1986.tbo578o

Pies, C., Barr, M., Strouse, C., \& Kotelchuck, M. (2016). Growing a best babies zone: lessons learned from the pilot phase of a multi-sector, placebased initiative to reduce infant mortality. Maternal Child Health Journal, 20, 968-973. doi: 10.1007/s10995-016-1969-1

Reynolds, M., Birzer, M., John, J., Wells, N., Anderson, B., \& Walker, D. (2015). Family Leaders and Workforce Leadership Development. Maternal Child Health Journal, 19, 252-256. doi: 10.1007/s10995-014-1617-6

Smith, D., Tiwari, R., \& Lommerse, M. (2014). Navigating Community Engagement. In R. 
Tiwari, M. Lommerse, \& D. Smith (Eds.) (2014).

M2 Models and Methodologies for Community

Engagement., Singapore: Springer.

Shediac-Rizkallah, M. \& Bone, L. (1998). Planning for the sustainability of community-based health programs: conceptual frameworks and future directions for research, practice and policy. Health Education Research, 13(1), 87-108.

Retrieved from

https://academic.oup.com/her/articlepdf/13/1/87/1664987/13-1-87.pdf

Wang, C. \& Burris, M. (1997). Photovoice: concept, methodology, and use for participatory needs assessment. Health Education Behavior, 24(3), 369-387. doi: 10.1177/109019819702400309

Whitehead, M. (1991). The Concepts and Principles of Equity and Health. Health Promotion International, 6(3), 217-228. Retrieved from https://doi.org/10.1093/heapro/6.3.217 